\title{
Management of a thyroid "incidentaloma" in a patient with cancer: a case report
}

This article was published in the following Dove Press journal:

International Medical Case Reports Journal

16 October 2015

Number of times this article has been viewed

\author{
Charles Dearman' \\ Esme J Hill' \\ Jamie M Franklin' \\ Greg P Sadler ${ }^{2}$ \\ Lai Mun Wang ${ }^{3}$ \\ Michael A Silva ${ }^{3}$ \\ Ricky A Sharma ${ }^{4}$ \\ 'Department of Oncology, \\ ${ }^{2}$ Department of Endocrine Surgery, \\ ${ }^{3}$ Department of Histopathology \\ and Hepatobiliary Surgery, ${ }^{4} \mathrm{CRUK}$ - \\ MRC Oxford Institute for Radiation \\ Oncology, NIHR Oxford Biomedical \\ Research Centre, Oxford University \\ Hospitals NHS Trust, University of \\ Oxford, Oxford, UK
}

\begin{abstract}
The routine use of ${ }^{18} \mathrm{~F}$-fluorodeoxyglucose-positron emission tomography (PET)/ computed tomography scans for staging and assessment of treatment response for cancer has resulted in a large number of thyroid abnormalities being detected as incidental findings ("incidentalomas"). Since most PET/CT scans are performed in the setting of a known nonthyroid malignancy, the need for "incidentalomas" to be further investigated and managed depends on the stage, prognosis, and current treatment plan for the known malignancy. We present a case describing the management of an incidental F-fluorodeoxyglucose-avid thyroid nodule detected in a patient with known metastatic colorectal cancer. On the basis of this case, we discuss the management of incidental PET-detected thyroid nodules in patients with metastatic cancer. Thyroid "incidentalomas" must be seen in the context of the prognosis and treatment plan for the known malignancy.
\end{abstract}

Keywords: cancer, imaging, metastasis, morbidity, surgery, PET

\section{Case report}

A 50-year-old female occupational therapist with a history of laparoscopic anterior resection 4 years previously for a T1 N0 M0 recto-sigmoid adenocarcinoma was found to have an elevated serum carcinoembryonic antigen (CEA) of $415.0 \mu \mathrm{g} / \mathrm{L}$ on surveillance blood testing. A computed tomography (CT) scan demonstrated a large mass in the left lobe of the liver involving the left and middle hepatic veins. Core biopsies demonstrated moderately differentiated adenocarcinoma, positive for CK20, CEA, and CDX2 and negative for CK7, TTF-1, and WT-1, consistent with metastatic colorectal cancer. Since the liver lesion was potentially operable, a ${ }^{18} \mathrm{~F}$-fluorodeoxyglucose-positron emission tomography (PET)/CT scan was arranged to check for occult extra-hepatic metastases. The PET/CT demonstrated a left iliac bone metastasis, retroperitoneal lymphadenopathy and a F-fluorodeoxyglucose (FDG)-avid thyroid nodule, reported as suspicious of malignancy (Figure 1).

Given the presence of extra-hepatic metastases, the patient was treated with 6 months of palliative oxaliplatin and modified de Gramont chemotherapy. Although the possibility of a primary thyroid cancer was considered, in the context of inoperable metastatic colorectal cancer, further investigation of the thyroid abnormality was not considered appropriate at that time. CT performed upon completion of treatment demonstrated partial response to chemotherapy: reduction of the liver metastasis, resolution of the retroperitoneal lymphadenopathy, and sclerosis of the right iliac bone metastasis. After 3 months, she underwent left hepatectomy and cholecystectomy, followed by
Correspondence: Ricky A Sharma Department of Oncology, Old Road Campus Building, University of Oxford, Oxford, OX3 7DQ, UK

Email ricky.sharma@oncology.ox.ac.uk (c) (i) (9) 2015 Dearman et al. This work is published by Dove Medical Press Limited, and licensed under Creative Commons Attribution - Non Commercial (unported, v3.0) BY LC License. The full terms of the License are available at http://creativecommons.org/licenses/by-nc/3.0/. Non-commercial uses of the work are permitted without any further permisson how to request permission may be found at: http://www.dovepress.com/permissions.php 


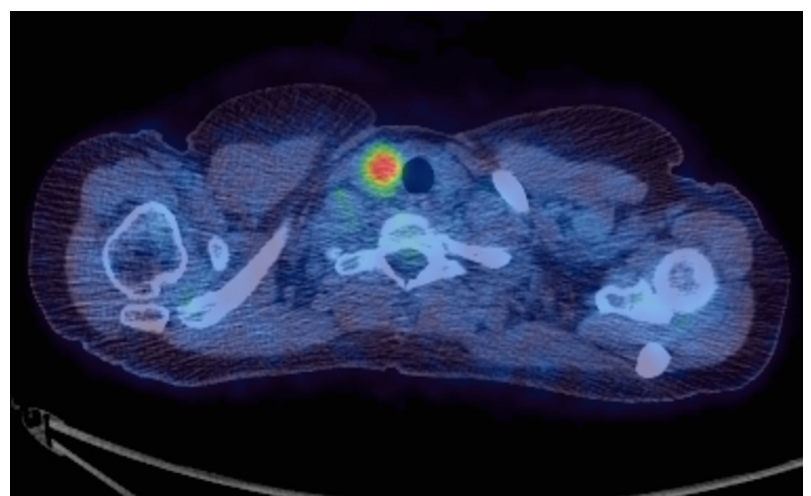

Figure I Axial fused I8F-FDG-PET/CT (SUV scale 0-6) demonstrating a FDG-avid (SUV max 7.8) nodule in the right lobe of the thyroid.

Abbreviations: 18F-FDG-PET/CT, ${ }^{18} \mathrm{~F}$-fluorodeoxyglucose-positron emission tomography/computed tomography; SUV, standardized uptake value.

radiotherapy to the left ilium 2 months later. She made a full recovery and CEA was undetectable $(<0.5 \mu \mathrm{g} / \mathrm{L})$ in serum. She was followed up by CT and serum CEA surveillance.

After 2 years of follow-up, a CT scan demonstrated progression of the thyroid nodule and serum CEA had risen to $2.2 \mu \mathrm{g} / \mathrm{L}$. Ultrasound-guided fine needle aspiration of the thyroid nodule was graded THY5 with glandular malignant cells, which were negative for TTF1 and positive for CDX2 by immunocytochemistry. This was consistent with metastatic colorectal adenocarcinoma, and, given that other disease sites had not changed over 2 years, the patient was offered a right hemi-thyroidectomy. Postoperative histology is shown in Figure 2. The patient is under CT and CEA surveillance and remains in remission 10 months later with undetectable serum CEA levels.

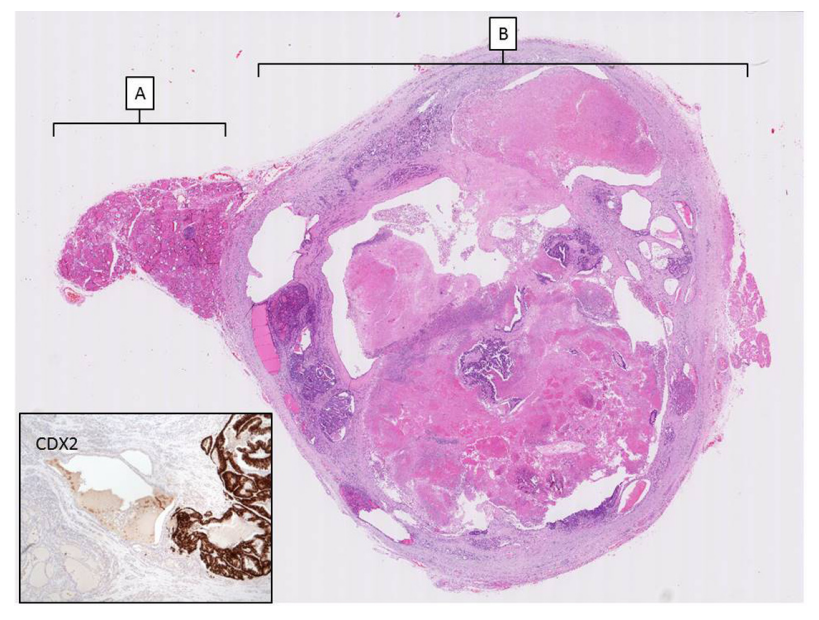

Figure 2 H\&E section from the hemithyroidectomy specimen (low power scan). Notes: (A) marks residual thyroid tissue and (B) denotes the $30 \mathrm{~mm}$ metastatic deposit of adenocarcinoma demonstrating prominent tumor necrosis. Inset with metastatic colonic adenocarcinoma confirmed by positive CDX2 immunohistochemistry.

Abbreviation: H\&E, Hematoxylin and eosin.

\section{Discussion}

Although benign and malignant "incidentalomas" are rare in routine clinical practice, ${ }^{1}$ some clinicians have claimed that widespread use of whole-body imaging examinations has led to increased detection of thyroid "incidentalomas"2 Two systematic reviews (55,160 and 125,754 subjects), analyzing studies using FDG/PET for various indications and patient populations, identified an incidence of focal FDG-avid thyroid lesions of $1 \%-1.6 \% .^{3,4}$ Malignancy was detected in $33 \%-34.8 \%$ of those with follow-up data available, of whom $81.3 \%-83 \%$ had papillary thyroid cancer (PTC), in keeping with the overall proportion of thyroid cancers that are PTCs. Of two studies reporting focal FDG-avid thyroid incidentalomas in patients with known or suspected nonthyroid malignancy, an incidence of $2.0 \%-3.9 \%$ was reported, with $34.7 \%-41.7 \%$ of these malignant lesions. ${ }^{5,6}$ In Kim et al's study, ${ }^{6}$ all incidentalomas operated upon were identified as PTCs.

There has been a debate over the need to treat all PTCs. Despite the threefold increase in the reported incidence of PTC over the last 3 decades, ${ }^{7}$ the death rate has remained stable. ${ }^{8}$ This is supported by the studies of active surveillance, which has not been associated with increased morbidity, ${ }^{9}$ and evidence of a significant burden of clinically occult PTC at autopsy. ${ }^{10}$ Follicular, medullary, and anaplastic thyroid cancers carry worse prognoses and are considered to require intervention unless the patient has a very poor prognosis from the known nonthyroid malignancy.

A retrospective study of 47,813 thyroidectomies performed for various indications, identified thyroid metastases in $0.13 \%$ of samples. ${ }^{11}$ Similar large data sets are not available for thyroidectomies performed only in patients with a known nonthyroid malignancy. Moreover, patients with thyroid metastases will typically have advanced malignancy and not proceed to thyroidectomy, so such data would underestimate the true incidence. In an autopsy series, the incidence was $1.9 \%-24 \%$ in patients with known malignancy. ${ }^{12}$ Cohort studies have suggested an association with renal cancer, ${ }^{13}$ although autopsy series indicate they are most commonly derived from lung, breast, and melanoma. ${ }^{12}$

This case emphasizes the importance of considering carefully whether or not to intervene when an incidental FDGavid thyroid nodule is detected in a patient with metastatic cancer. Appropriate investigation and management depend on the disease stage, patient's performance status, prognosis, and treatment plan for the known nonthyroid cancer, and whether or not the thyroid abnormality is symptomatic. If there are symptoms, ultrasound and fine needle aspiration for tissue 
diagnosis is warranted, and multidisciplinary team discussion involving an endocrine surgeon prior to considering further investigation and treatment.

For asymptomatic patients, further investigation of FDGavid thyroid lesions is only appropriate where demonstrating either metastatic disease to the thyroid or a more aggressive thyroid cancer will alter management strategy for that individual patient. The patient in our report had inoperable metastatic disease, so the "incidentaloma" was not considered likely to affect clinical outcome. However, after the patient underwent potentially curative liver surgery and high-dose radiotherapy, and completed follow-up for 2 years, it became appropriate to further assess the thyroid lesion.

One study recruited 43 patients with metastases to the thyroid gland and reported a longer survival (34 vs 25 months) for those undergoing surgery than in subjects treated nonsurgically. ${ }^{14}$ This was not replicated in another nonrandomized study of 36 patients with metastasis to the thyroid in which 21 patients received surgery versus 15 that did not. ${ }^{11}$ There was no statistical difference in overall survival despite the worse clinical situation of the nonsurgical cohort. Therefore with such weak evidence available, in patients suitable for intervention for their "incidentaloma," surgery is generally the treatment of choice for solitary thyroid metastasis and for known thyroid metastasis in patients where other extrathyroid metastases are resectable. ${ }^{13}$ Patients must be counseled regarding the $1 \%-6 \%$ risk of surgical complications associated with thyroidectomy, including vocal cord paralysis, hypothyroidism, and hypoparathyroidism. ${ }^{2}$

In summary, FDG-avid thyroid nodules occur relatively frequently. On finding thyroid "incidentalomas" in patients with a history of cancer, metastasis should be considered, even though the majority of these lesions will be benign or PTC. Thyroid "incidentalomas" must be seen in the context of the prognosis and treatment plan for the known malignancy.

\section{Acknowledgments}

Written consent was taken from this patient for the publication of this article. This required no further review by an NHS Research Ethics Committee. We thank the patient for consenting to publication of the case report. RAS is funded by the CRUK-EPSRC Oxford Cancer Imaging Centre, the Bobby Moore Fund of Cancer Research UK and the NIHR Biomedical Research Centre Oxford.

\section{Disclosure}

The authors report no conflicts of interest in this work.

\section{References}

1. Uppal A, White MG, Aschebrook-Kilfoy B, et al. Benign and malignant thyroid incidentalomas are rare in routine clinical practice: a review of 97,908 imaging studies. Cancer Epidemiol Biomarkers Prev. 2015;24(9);1-5.

2. Brito JP, Morris JC, Montori VM. Thyroid cancer: zealous imaging has increased detection and treatment of low risk tumours. BMJ. 2013;347:f4706.

3. Shie P, Cardarelli R, Sprawls K, Fulda KG, Taur A. Systematic review: prevalence of malignant incidental thyroid nodules identified on fluorine-18 fluorodeoxyglucose positron emission tomography. $\mathrm{Nucl}$ Med Commun. 2009;30(9):742-748.

4. Soelberg KK, Bonnema SJ, Brix TH, Hegedus L. Risk of malignancy in thyroid incidentalomas detected by ${ }^{18} \mathrm{~F}$-fluorodeoxyglucose positron emission tomography: a systematic review. Thyroid. 2012; 22(9):918-925.

5. Kalender E, Elboga U, Celen YZ, et al. Incidental thyroid lesions detected with FDG PET scanning. Acta Medica Mediterr. 2014;30:497-501.

6. Kim H, Kim SJ, Kim IJ, Kim K. Thyroid incidentalomas on FDG $\mathrm{PET} / \mathrm{CT}$ in patients with non-thyroid cancer - a large retrospective monocentric study. Onkologie. 2013;36(5):260-264.

7. Ferlay J, Bray F, Steliarova-Foucher E, Forman D. Cancer Incidence in Five Continents, CI5plus. IARC CancerBase No 9 Lyon: International Agency for Research on Cancer; 2014. Available from: http://ci5.iarc.fr. Accessed July 20, 2015.

8. Howlader N, Noone AM, Krapcho M, et al. SEER Cancer Statistics Review; 1975-2012. Available from: http://seer.cancer.gov/ csr/1975_2009_pops09. Accessed July 20, 2015.

9. Ito Y, Miyauchi A, Inoue H, et al. An observational trial for papillary thyroid microcarcinoma in Japanese patients. World J Surg. 2010;34(1):28-35.

10. Harach HR, Franssila KO Wasenius VM. Occult papillary carcinoma of the thyroid. A "normal" finding in Finland. A systematic autopsy study. Cancer. 1985;56(3):531-538.

11. Papi G, Fadda G, Corsello SM, et al. Metastases to the thyroid gland: prevalence, clinicopathological aspects and prognosis: a 10-year experience. Clin Endocrinol (Oxf). 2007;66(4):565-571.

12. Wood K, Vini L, Harmer C. Metastases to the thyroid gland: the Royal Marsden experience. Eur J Surg Oncol. 2004;30(6):583-588.

13. Mirallie E, Rigaud J, Mathonnet M, et al. Management and prognosis of metastases to the thyroid gland. J Am Coll Surg. 2005;200(2): 203-207.

14. Nakhjavani MK, Gharib H, Goellner JR, van Heerden JA. Metastasis to the thyroid gland. A report of 43 cases. Cancer. 1997;79(3):574-578.
International Medical Case Reports Journal

\section{Publish your work in this journal}

The International Medical Case Reports Journal is an international, peer-reviewed open-access journal publishing original case reports from all medical specialties. Previously unpublished medical posters are also accepted relating to any area of clinical or preclinical science. Submissions should not normally exceed 2,000 words or

\section{Dovepress}

4 published pages including figures, diagrams and references. The manuscript management system is completely online and includes a very quick and fair peer-review system, which is all easy to use. Visit http://www.dovepress.com/testimonials.php to read real quotes from published authors. 